\title{
A Brief Outlook on Pharmacogenetics (PGx): Focus in MicroRNAs (miRNAs) and Cancer Stem Cells (CSCs)
}

\author{
Ferry Sandra* \\ Department of Biochemistry and Molecular Biology, Division of Oral Biology, Faculty of Dentistry, Trisakti University, \\ Jakarta, Indonesia
}

\begin{abstract}
It has been known that there are differences in response to medications both in terms of clinical activity and side effects. Among all influencing factors, genetic variation has been considered to play a crucial part. By genetic investigation, the differences in drug metabolism, transport and target could be disclosed. Termed as "pharmacogenetics (PGx)", that focuses on the variants within one or more candidate genes. Genetic tests have been started for screening polymorphisms prior to drug prescription, moreover many biomarkers were developed in oncology. Recent PGx investigations have been conducted to identify mRNAs, microRNAs (miRNAs) and other downstream signals that are affected by variation in genes that might cause drug response variability. Another intriguing study related to PGX in cancer stem cells (CSCs) has recently aroused. CSC shows more resistant behavior to drug. CSCs are subpopulation of cells, which share some same markers with stem cells. CSC can induce specific signal transduction pathways. Variation in genes affect CSCs activity are generally neglected in the past PGx studies. This could be one of the explanation why past PGX studies in cancer cell do not achieve optimalclinical outcome.
\end{abstract}

Keywords : pharmacogenetics, pharmacogenomics, microRNAs, cancer stem cells

\section{INTRODUCTION}

Age, race/ethnicity, weight, gender, concomitant diseases and drugs, social factors and genetics and many others can affect drug response. Among these factors, variation in genes plays important role in the variation in drug response. Pharmacogenetics (PGx) studies have been trying to correlate genetic variability with human drug response variability. Since understanding in association of genes with diseases and drug responses getting improved, clinical genetic tests may emerge to enrich conventional methods of assessing drug responses and diseases.
Recent PGx investigations have been started to identify mRNAs, microRNAs (miRNAs) and other downstream signals that are affected by variation in genes. These that might cause drug response variability. Although thousand genomes have been sequenced, the task is still remained to transform the information for the purpose of personal health identification as well as personalized treatment

Submitted: December 14, 2018

Revised: January 17, 2019

Accepted: January 17, 2019

*Corresponding author: ferrysandra@gmail.com 
strategies. Since there is patient-to-patient variation in drug response, the treatment can't be generalized. The treatment should be tailored based on the detected unique genes of each individu. With personalized treatment, the benefit can be maximized, while the risk of adverse side effects can be minimized (Madian, et al., 2012).

\section{PGx}

Age, Genes that cause differences in drug response is correlated with variation in genes involved in the drug pharmacokinetics including the absorbance, metabolization, distribution, and excretion. Besides the drug pharmacokinetics, the drug pharmacodynamics including drug-target interaction and mechanism of action, are also correlated (Salari, et al., 2012). Single nucleotide polymorphisms (SNPs) can now be genotyped at high thoughput and relatively affordable. Therefore, characterization of novel polymorphisms and rare mutations should be pursued (Madian, et al., 2012).

PGx have been widely conducted in oncology. Expression of somatic genetic changes in tumor can markedly elevate or decrease compared with normal tissue (Salari, et al., 2012). Therefore, genetic analysis of tumor gene expression can provide information of therapeutic target, i.e., Human Epidermal Receptor 2 (HER2) in breast cancers, epidermal growth factor receptor (EGFR) in lung cancers, Philadelphia chromosome in chronic myelogenous leukaemias (Salari, et al., 2012). Mutations in tumors can be used to anticipate resistance of targeted drug, for example in colorectal cancers, the V-Kiras2 Kirsten rat sarcoma viral oncogene homolog (KRAS) mutations can be used to approach the use of cetuximab and panitumumab as EGFR-specific antibodies/targeted drug (Salari, et al., 2012; Amado, et al., 2008; Karapetis, et al., 2008; van Cutsem, et al., 2009).

In cardiovascular, warfarin dose varies by over 10 -fold, meanwhile the therapeutic window is narrow. The variation is related with 3 variants in cytochrome $\mathrm{P} 450$, family 4, subfamily $\mathrm{F}$, polypeptide 2 (CYP4F2), CYP2C9, and vitamin K epoxide reductase complex, subunit 1 (VKORC1). (Salari, et al., 2012; Caldwell, et al., 2008; Rieder, et al., 2005; Sconce, et al., 2005; Takahashi, et al., 2006).

\section{miRNA IN PGx}

miRNA is a small non-coding RNAs. miRNA conserves of 21-25 nucleotides in length. miRNA has been reported to be able to down-regulate gene expression gene expression at the level of posttranscription (Zhang and Dolan, 2010). Not only in mammals, miRNAs can be found in genomes of plants, worms and flies (Zhang and Dolan, 2010; Lee, et al., 2007). More than 700 miRNAs have been identified in humans based on experimental research and bioinformatic study (Zhang and Dolan, 2010; Griffiths-Jones, et al., 2008).

miRNAs play important roles in gene expression regulatory. miRNA binds to the 3 ' untranslated regions (3'UTRs) of the gene traget and reduces gene expression at the level of posttranscription.(Zhang and Dolan, 2010; $\mathrm{He}$ and Gregory, 2004) miRNAs have been reported to be correlated with various cancers, including leukemia (Garzon, et al., 2008), prostate cancer (Ambs, et al., 2008), gastric cancer (Ueda, et al., 2010), lung cancer (Wu, et al., 2009), breast cancer (Khoshnaw, et al., 2009), and liver cancer (Mott, et al., 2009). miRNAs could affect the cancer in the initiation and progression stages (Garzon, et al., 2009). miRNAs have been reported to invove in prognosis of cancer as well. Not only exixtence of miRNAs, but its alteration is also correlated with various cancers (Garzon, et al., 2009).

miRNAs may also contribute to drug response, for example through regulating key drug metabolizing genes such as CYP. For example, the escape of miR-519c by 3'UTR truncation was found to enable drug-resistant cells to maintain high expression of ATP-binding cassette (ABC), subfamily $\mathrm{G}$, member 2 (ABCG2), a transporter that is 
related to the absorption, distribution and excretion of drugs and cytotoxins (To, et al., 2009; Zhang and Dolan, 2010).

miR-451 and miR-27a were found to increase the expression of $\mathrm{P}$-glycoprotein, $\mathrm{ABC}$, subfamily $\mathrm{B}$, member 1 (ABCB1) gene product that affect cancer cells resistance to a broad range of chemotherapeutic agents (Zhu, et al., 2008) Particularly, the expressions of miR-451 and miR$27 \mathrm{a}$ are up-regulated in some multidrug resistant cancer cell lines, as compared with their parental lines.(22) In another study, a SNP of miR-146a precursor was demonstrated to affect its binding to the 3'UTRs of breast cancer 1, early onset (BRCA1) as well as BRCA2 mRNAs, thus potentially modulating their expression.(Zhang and Dolan, 2010; Shen, et al., 2008).

\section{CSC IN PGX}

Identified based on surface markers, enzymatic activity, or drug-efflux transporters, CSCs can form tumor when injected into immunologically deficient mice (Bonnet and Dick, 1997). Based on cell type and marker, frequency of CSCs can be found $\sim 20 \%$ (Crea, et al., 2011) CSC can be specified by key signaling pathways. The signaling pathway is composed by a definite group of genes. Wnt, Notch and Hedgehog have been reported as the principal signaling pathways of CSC selfrenewal (Crea, et al., 2011). There are CSC-specific pathways that contribute to CSC drug resistance (Crea, et al., 2011). Hedgehog pathway has been reported to play important role in the maintenance of CSCs (Crea, et al., 2011). For example, proliferation and survival of CD133+ glioma CSCs were shown relied on Hedgehog pathway (Clement, et al., 2007; Ehtesham, et al., 2007) Major signaling pathways in normal stem cells regulating proliferation and differentiation were also shown to be the key player in CSCs. These pathways could be suggested as the target for CSC eradication (Crea, et al., 2011) or CSC reprogram (Wijaya, et al., 2011).
Expression of CD133 was reported to be correlated with poor survival in colorectal cancer (Artells, et al., 2010) and glioblastoma (Pallini, et al., 2008). Expression of CD133 was also correlated with expression of drug resistance genes in nonsmall cell lung cancer (NSCLC) (Salnikov, et al., 2010). In addition, CD133 was reported to be correlated with premalignancy in oral tissue (Amtha, et al., 2015). Meanwhile CD44 expression was reported to be correlated with the risk of metastasis in gastric (Okayama, et al., 2009) and breast cancers (Celebiler Cavusoglu, et al., 2009). All disclosed gene expression profiles of CSCrelated pathways are useful for future pharmacogenomicdevelopment.

\section{CONCLUSION}

PGx studies in miRNAs and CSCs have enriched personalized treatment strategies, so that each individual could have tailored treatment in attempts to maximize therapeutic benefit and minimize side effects. Therefore earlier PGx studies those correlating genetic variability with human drug response variability should be added with miRNAs which play important regulatory roles in gene expression, and CSCs markers which are highly related with drug resistance and poor survival.

\section{REFERENCES}

Ambs, S., Prueitt, R.L., Yi, M., Hudson, R.S., Howe, T.M., Petrocca, F., et al., 2008, Genomic Profiling of MicroRNA and Messenger RNA Reveals Deregulated MicroRNA Expression in Prostate Cancer, Cancer Res., 68(15), 6162-6170.

Amado, R.G., Wolf, M., Peeters, M., Van Cutsem, E., Siena, S., Freeman, D.J., et al., 2008, Wildtype KRAS is Required for Panitumumab Efficacy in Patients with Metastatic Colorectal Cancer, J. Clin. Oncol., 26(10), 1626-1634.

Amtha, R., Gunardi, I., Sandra, F., Ernawati, D.S., 2015, Expression of CD133 in Carious Premalignant and Proliferative Lesions, Dent J., 48(2), 65-69. 
Artells, R., Moreno, I., Díaz, T., Martínez, F., Gel, B., Navarro, A., et al., 2010, Tumour CD133 mRNA Expression and Clinical Outcome in Surgically Resected Colorectal Cancer Patients, Eur. J. Cancer, 46, 642-649.

Bonnet, D. and Dick, J.E., 1997, Human Acute Myeloid Leukemia is Organized as A Hierarchy that Originates from A Primitive Hematopoietic Cell, Nat. Med., 3(7), 730-737.

Caldwell, M.D., Awad, T., Johnson, J.A., Gage, B.F., Falkowski, M., Gardina, P., et al., 2008, CYP4F2 Genetic Variant Alters Required Warfarin Dose, Blood, 111(8), 4106-4112.

Celebiler Cavusoglu, A., Kilic, Y., Saydam, S., Canda, T., Bașkan, Z., Sevinc, A.I., et al., 2009, Predicting Invasive Phenotype with $\mathrm{CDH} 1$, CDH13, CD44, and TIMP3 Gene Expression in Primary Breast Cancer, Cancer Sci., 100(2), 2341-2345.

Clement, V., Sanchez, P., de Tribolet, N., Radovanovic, I. and Ruiz i Altaba, A., 2007, HEDGEHOG-GLI1 Signaling Regulates Human Glioma Growth, Cancer Stem Cell Self-renewal, and Tumorigenicity, Curr. Biol., 17(2), 165-172.

Crea, F., Duhagon, M.A., Farrar, W.L. and Danesi, R., 2011, Pharmacogenomics and Cancer Stem Cells: A Changing Landscape?, Trends Pharmacol. Sci., 32(8), 487-494.

Ehtesham, M., Sarangi, A., Valadez, J.G., Chanthaphaychith, S., Becher, M.W., Abel, T.W., et al., 2007, Ligand-dependent Activation of the Hedgehog Pathway in Glioma Progenitor Cells, Oncogene, 26(39), 5752-5761.

Garzon, R., Calin, G.A., Croce, C.M., 2009, MicroRNAs in Cancer, Annu. Rev. Med., 60, 167-179.

Garzon, R., Volinia, S., Liu, C.G., FernandezCymering, C., Palumbo, T., Pichiorri, F., et al., 2008, Microrna Signatures Associated with Cytogenetics and Prognosis in Acute Myeloid Leukemia, Blood, 111(6), 3183-3189.

Griffiths-Jones, S., Saini, H.K., van Dongen, S. and Enright, A.J., 2008, Mirbase: Tools for MicroRNA Genomics, Nucleic Acids Res., 36(Database issue): D154-D158.

He, L. and Gregory, J.H., 2004, Microrna: Small RNAs with A Big Role in Gene Regulation, Nat. Rev. Genet., 5(7), 522-531.
Karapetis, C.S., Khambata-Ford, S., Jonker, D.J., O'Callaghan, C.J., Tu, D., Tebbutt, N.C., et al., 2008, K-ras Mutations and Benefit from Cetuximab in Advanced Colorectal Cancer, $N$. Engl. J. Med., 359(17), 1757-1765.

Khoshnaw, S.M., Green, A.R., Powe, D.G. and Ellis, I.O., 2009, MicroRNA Involvement in the Pathogenesis and Management of Breast Cancer, J. Clin. Pathol., 62(5), 422-428.

Lee, C.T., Risom, T. and Strauss, W.M., 2007, Evolutionary Conservation of MicroRNA Regulatory Circuits: An Examination of MicroRNA Gene Complexity and Conserved MicroRNAtarget Interactions through Metazoan Phylogeny, DNA Cell. Biol., 26(4), 209-18.

Madian, A.G., Wheeler, H.E., Jones, R.B. and Dolan, M.E., 2012, Relating Human Genetic Variation to Variation in Drug Responses, Trends. Genet., 28(10), 487-495.

Mott, J.L., 2009, MicroRNAs Involved in Tumor Suppressor and Oncogene Pathways: Implications for Hepatobiliary Neoplasia, Hepatology, 50(2), 630-637.

Okayama, H., Kumamoto, K., Saitou, K., Hayase, S., Kofunato, Y., Sato, Y. , et al., 2009, CD44v6, MMP. 7 and Nuclear Cdx2 are Significant Biomarkers for Prediction of Lymph Node Metastasis in Primary Gastric Cancer, Oncol. Rep., 22(4), 745-755.

Pallini, R., Ricci-Vitiani, L., Banna, G.L., Signore, M., Lombardi, D., Todaro, M., et al., 2008, Cancer Stem Cell Analysis and Clinical Outcome in Patients with Glioblastoma Multiforme, Clin. Cancer Res., 14(24), 8205-8212.

Rieder, M.J., Reiner, A.P., Gage, B.F., Nickerson, D.A., Eby, C.S., McLeod, H.L., et al., 2005, Effect of VKORC1 Haplotypes on Transcriptional Regulation and Warfarin Dose, N. Engl. J. Med., 352(22), 2285-2293.

Salari, K., Watkins, H. and Ashley, E.A., 2012, Personalized Medicine: Hope or Hype?, Eur. Heart J., 33(13), 1564-1570.

Salnikov, A.V., Gladkich, J., Moldenhauer, G., Volm, M., Mattern, J. and Herr, I., 2009, CD133 is Indicative for A Resistance Phenotype but Does Not Represent A Prognostic Marker for Survival of Non-small Cell Lung Cancer Patients, Int. J. Cancer, 126(4), 950-958. 
Sconce, E.A., Khan, T.I., Wynne, H.A., Avery, P., Monkhouse, L., King, B.P., et al., 2005, The Impact of CYP2C9 and VKORC1 Genetic Polymorphism and Patient Characteristics upon Warfarin Dose Requirements: Proposal for A New Dosing Regimen, Blood, 106(7), 2329-2333.

Shen, J., Ambrosone, C.B., DiCioccio, R.A., Odunsi, K., Lele, S.B. and Zhao, H., 2008, A Functional Polymorphism in the Mir-146a Gene and Age of Familial Breast/Ovarian Cancer Diagnosis, Carcinogenesis, 29(10), 1963-1966.

Takahashi, H., Wilkinson, G.R., Nutescu, E.A., Morita, T., Ritchie, M.D., Scordo, M.G., et al., 2006, Different Contributions of Polymorphisms in VKORC1 and CYP2C9 to Intra- and Interpopulation Differences in Maintenance Dose of Warfarin in Japanese, Caucasians and AfricanAmericans, Pharmacogenet. Genomics., 16(2), 101-110.

To, K.K., Robey, R.W., Knutsen, T., Zhan, Z., Ried, T. and Bates, S.E., 2009, Escape from hsamir-519c Enables Drugresistant Cells to Maintain High Expression of abcg2, Mol. Cancer Ther., 8(10), 2959-2968.

Ueda, T., Volinia, S., Okumura, H., Shimizu, M., Taccioli, C., Rossi, S., et al., 2010, Relation between MicroRNA Expression and Progression and Prognosis of Gastric Cancer: A MicroRNA Expression Analysis, Lancet Oncol., 11(2), 136146.

Van Cutsem, E., Kohne, C.H., Hitre, E., Zaluski, J., Chang-Chien, C.R., Makhson, A., et al., 2009, Cetuximab and Chemotherapy as Initial Treatment for Metastatic Colorectal Cancer, $N$. Engl. J. Med., 360(14), 1408-1417.

Wijaya, L., Agustina, D., Lizandi, A.O., Kartawinata, M.M. and Sandra, F., 2011, Reversing Breast Cancer Stem Cell into Breast Somatic Stem Cell, Curr. Pharm. Biotechnol., 12(2), 189-195.

Wu, X., Piper-Hunter, M.G., Crawford, M., Nuovo, G.J., Marsh, C.B., Otterson, G.A., et al., 2009, MicroRNAs in the Pathogenesis of Lung Cancer, J. Thorac Oncol., 4(8), 1028-1034.

Zhang, W. and Dolan, M.E., 2010, The Emerging Role of microRNAs in Drug Response, Curr. Opin. Mol. Ther., 12(6), 695-702.

Zhu, H., Wu, H., Liu, X., Evans, B.R., Medina, D.J., Liu, C.G. and Yang, J.M., 2008, Role of MicroRNA mir-27a and mir-451 in the Regulation of $\mathrm{mdr} 1 / \mathrm{p}$ - Glycoprotein Expression in Human Cancer Cells, Biochem. Pharmacol., 76(5), 582588. 